\title{
Profits: Mean Diverting with High Volatility
}

\author{
John Silvia, Chief Economist \\ Wells Fargo Securities, LLC \\ One Wachovia Center, 301 South College Street, NC0602 \\ Charlotte, NC 28288-0602, USA
}

Tel: 1-704-374-703 Fax: 1-704-383-3102Ｅ-mail: john.silvia@wellsfargo.com

\author{
Azhar Iqbal \\ Vice President and Econometrician (Corresponding Author) \\ Wells Fargo Securities, LLC, One Wachovia Center, 301 South College Street, NC0602 \\ Charlotte, NC 28288-0602, USA
}

Tel: 1-704-383-6805 Fax: 1-704-383-3102 E-mail: azhar.iqbal@wellsfargo.com

Received: August 13, $2010 \quad$ Accepted: September 13, $2010 \quad$ doi:10.5539/ijef.v3n2p200

\begin{abstract}
Even though the behavior of the U.S. profit growth varies over the economic cycle that variation itself drives investor behavior and asset prices. We raise three fundamental questions which are; first, does profit growth over time exhibit a mean-reverting behavior? Second, how volatile are profits and does this volatility obscure the message of profit growth? Finally, do profit growth rates vary between decades/ sub-samples?

Our efforts suggest that since 1970 the mean and standard deviation of profit growth had actually been decreasing up until 1990s. For the most recent (2000-08) period, the profit growth shows an up-tick in both the mean and the standard deviation. For the entire period, 1970-2008, we find that the trend coefficient is statistically insignificant.

We apply the traditional unit root tests, efficient unit root tests, and unit root tests with structural break on the profits series. In addition, we follow Hamilton's approach and apply an ARCH approach on the profits series.

Our empirical findings are consistent with the Schumpeter's view, mean-diversion with a possibility of deviation from long-run trend growth. In addition to the factors introduced by Schumpeter there may be some exogenous shocks which could alter the long-run path of the profits.
\end{abstract}

Keywords: Corporate Profits, Structural Change, Unit Root, ARCH, Mean-Diversion

JEL Classification: C2; C220; E22.

Introduction

The search for profits by entrepreneurs and corporate leaders is one of the key incentives to technology development, efficient organization, as well as physical and human capital investment. Yet, while profits are core to economic performance they are also known to vary significantly with the business cycle. This paper seeks to characterize the behavior of profits over the economic cycle. We raise three fundamental questions which are; first, does the profit growth over time exhibit a mean-reverting behavior? That is, does the growth in profits exhibit a tendency to return to some average value? Second, how volatile are profits and does this volatility obscure the message of profit growth? Finally, do profit growth rates vary between decades/ sub-samples?

Traditional economic theory explains that profits in the long-run return to their normal level and thereby mean-reversion. On the other hand, Schumpeter $(1934,1950)$ suggested the idea of a "creative destruction," that is, profits may deviate from their normal level and sometime this deviation leads to another (new) equilibrium, hence not mean-reversion. Empirically, researchers have found evidence in support of both views. For example, Mueller $(1977,1990)$ is among the first who provides empirical evidence, that is, in the long-run profits return to their normal level. On the other hand, evidence of long-run profits beyond normal profits can be found in Lipczinsky and Wilson (2001), see next section for more detail.

Researcher in the past, have had applied traditional unit root tests (introduced by Dickey-Fuller (ADF), Phillips-Perron (PP), and Kwiatkowski-Phillips-Schmidt-Shin (KPSS)) on the profits using micro-level data (firms and industries profits) as well as macro-level data (aggregate profits). However, these unit root tests have serious issues and recent literature proposed to employ efficient unit root tests introduced by Elliot-Rothenberg-Stock and 
Ng-Perron (see Silvia and Iqbal; 2009 for more detail). In simple words, results based on the traditional unit root tests are not reliable. Our study, best of our knowledge (BOK), is the first who apply efficient unit root test on profits time series. Another important but missing element in the literature is the issue of a structural change. For instance, Schumpeter's creative destruction, in simple words, is a structural change because when deviation from normal profits leads to a new equilibrium and that may be a break in the long-term trend growth of the profits. Moreover, in practice, in case of USA, there are many factors which could cause a structural break in the profits i.e., 1973 oil price shock (see foot note 16 for more detail). But no one in the literature, BOK, has had tested empirically the issues of a structural break in the profits. Therefore, our study is the first who apply unit root test with structural break on the profits. Some researchers did mention the possibility of deviation of profits from their normal level (see next section for more detail) but we are the first, BOK, who examine, econometrically, and we employ an ARCH approach to test whether or not deviation from the long-run trend growth of the profits is statistically significant. Finally, we provide a complete econometric framework to test: whether profit growth is mean-reverting, contains a structural break, and deviation from long-run trend growth is statistically significant or not. It is worthwhile to mention that we use aggregate profits data (macro-level data) but our proposed econometric framework is also valid (and more appropriate than the procedure used in the literature) for firms and industries profits (micro-level data).

In this paper we divide the U.S. profit growth rate (Note 1) into decades since 1970. We test if all data share the same statistical moments - average and standard deviation. We also estimate a stability ratio, the standard deviation as a percent of mean. In addition, we test whether there is any change in the character (linear vs. nonlinear) of the trend in profit growth over time. The next issue would be to test whether profit growth is mean-reverting or not. We employ unit root methodology on the series and test whether profit growth contains a unit root or not. If a series does not contain unit root we call it stationary and, otherwise, non-stationary. Moreover, a stationary series fluctuates around a constant long run mean that implies the series, profit growth in this case, has a finite variance which does not depend on time, hence mean reversion. On the other hand, if a series is non-stationary (contains unit root) that implies the series has no tendency to return to the long run mean and the variance of the series is time dependent. Therefore, the best way to test whether the profit growth series is mean reverting would be to test whether profit growth contains a unit root (not mean reversion) or not (mean reversion). We employ a comprehensive unit root methodology(Note 2) and use traditional unit root tests (ADF, PP, KPSS), efficient unit root test (introduced by Elliot-Rothenberg-Stock and Ng-Perron), and unit root tests with structural breaks (introduced by Perron, Zivot-Andrews, and Kim-Perron) on the U.S. profit growth rate series and test whether the profits series is mean reverting.

Recently, Hamilton (2008) proposed the use of ARCH approach in macroeconomics and suggested that even our primary objective is the estimation of the conditional mean (mean reversion or not) having a correct description of the conditional variance (volatility of the series) can still be quite important for two reasons. First, OLS standard errors can be misleading, with a spurious regression possibility in which a true null hypothesis is asymptotically rejected with probability one. Second, the inference about the conditional mean can be inappropriately influenced by outliers and high-variance episodes. Consequently, if we incorporate the conditional variance directly into the estimation of the mean then the estimates of the mean would be more efficient (see Hamilton; 2008 for more detail). Therefore, we utilize the ARCH approach.

Our efforts suggest that since 1970 the mean and standard deviation of profit growth had actually been decreasing up until 1990s. For the most recent (2000-08) period, the profit growth shows an uptick in both the mean and the standard deviation. For the entire sample period (1970-2008), a higher standard deviation (12.43\%) than the mean $(8.19 \%)$ is evidence of high volatility in the profits series. Indeed, such volatility is very high as pictured by Figure 1 and that therefore the growth of profits is very volatile over time. In addition, our empirical analysis find that the level of the U.S. profit growth rates is mean diverting and subject to a structural break. Moreover, the ARCH effect in the profit growth series implies the profit series has a volatility cluster-the deviation from the mean is not constant over time and that the deviation is smaller for some periods than others, and vice versa.

Our findings are consistent with the Schumpeter's view, that is, profits growth is mean-diverting with a possibility of deviation from long-run trend growth. In addition to the factors introduced by the Schumpeter there may be some exogenous shocks which could alter the long-run path of profit growth.

The rest of the paper is organized as follows. In section 2 we discuss theory and data for the corporate profit growth. Section 3 introduces the econometric set-up of the study and section 4 explains the results. The concluding remarks of the paper are discussing in section 5 .

\section{Profit as Return on Capital: A Review of the Theory and Data}

Corporate profits represent the return to business leaders for three specific economic decisions. First, there is the saving/consumption decision. Entrepreneurs will postpone consumption in order to invest in the business. Profits therefore represent, in part, the return to entrepreneurs that delay consumption to save and invest in an enterprise. 
Second, profits (reward) are the returns for those willing to take risks.(Note 3) On average, entrepreneurs who take risks will earn a higher rate of return on their investments than those who invest more cautiously. Finally, profits are a return to the innovation of an entrepreneur for her organizational ability or marketing insights. The entrepreneur generates profits by a better organization of marketing or delivering a new product or by inventing a new product or process.

How do profits fit into the economy? Corporate profits tend to be the most cyclical income component in the economy. Whereas wage and interest income are the result of contractual obligations, profits are what is left over after all expenses are paid. Since profits are the residual or the difference between revenues and costs, then profits tend to be very volatile over the business cycle. Yet, in contrast, over the long run, profits tend to be a steady share of income. This is consistent with the expectation of a sustained capital-output ratio that would be fit with the long run equilibrium of the economy. (Note 4) Over the last twenty years, the increasing use of debt rather than equity finance, however, has reduced the measured share of the return on capital that is actually recorded as profits rather than as interest. (Note 5)

Now the question arise; does economic theory provides an expected growth trend of the profit over time? The answer is yes. Traditional economic theory usually sustains the notion that the deviation from normal profit could be diluted in the long-run as a result of entry and exit of firms, hence mean-reversion. The process which restores profits to a normal level is pretty much straightforward. For example, any economic activity that yields excess profits or is unprofitable to stimulate either entry or exit. Moreover, this dynamic process will eventually bring profits to their long-run trend growth level. On the other hand, Schumpeter $(1934,1950)$ proposed a different view that is known as "creative destruction". Schumpeter (1934, chapter 2) suggested that deviation from equilibrium may leads to another (new) equilibrium. That could happened due to: the introduction of a new good, new method of production, opening of a new market, new source of inputs supply, and the carrying out of the new organization of any industry. Therefore, deviation from the normal profits, long-run trend growth, is possible and sometime it creates a new equilibrium, in other words not mean-reversion.

We have discussed the theoretical views about the profits and now we take a look at the empirical evidence about the long-run growth trend of the profits. Many researchers have examined whether or not the profit is mean-reversion using micro-level data (firms and industries profits) and macro-level data (aggregate profits). Mueller (1977) is among the first who empirically examined the mean-reversion properties of the profits and he also collected work on this topic in Mueller (1990). He suggested that in the long-run profits return to their normal level. On the other hand, Lipczinsky and Wilson (2001) provided a relatively recent survey on this topic and suggested that empirical findings are somewhat mixed as also evidence of long-run profits beyond normal profits are found. Vctum (1995) used aggregate profits data series for USA, Germany, Japan, and Canada and concluded that profits is non-stationary, not mean-reversion, at level form for all four countries. On the other hand, Giovanni and Parguez (2005) used U.S.'s aggregate profits time series and suggested that profit is mean-reverting, profits in the long-run return to their normal path.

Summing up, literature provides somewhat mixed empirical evidence about the long-run behavior of the profits. That being said, some researchers (including Mueller (1990)) findings are consistent with the traditional economic view, i.e. profits in the long-run return to their normal growth pattern, hence mean-reversion. On the other hand, researchers' findings are suggesting the Schumpeter's view of the profits (evidence can be found in Lipczinsky and Wilson (2001)), that is, profit is not mean-reversion, does not return to the long-run path. One would ask; which view is accurate? To answer this question we follow a better and recently introduced econometric techniques and provide a complete econometric framework to analyze whether profits is mean-reversion (traditional economic view) or not-leads to a new equilibrium (Schumpeter's view).

Our profit growth (Note 6) analysis begins with 1970:Q1. We do not extend back to the end of the World-War-II (WWII) because the U.S. economy could not function properly by mid or late 1960s. For instance, the U.S. economy slipped five times into recession between the end of the WWII and 1965. Therefore, the start date for our analysis is 1970:Q1. We divide the data series into four decades (1970-79, 1980-89, 1990-99 and 2000-08); the fourth is not a complete decade. Other possible choices could have been to divide the data into business cycles, from trough to peak, etc. Although, data division according to the business cycle is a good choice, it does not fit into our analysis. For instance, each business cycle does not equal in duration and the duration varies from 4 quarters to 30 quarters. Moreover, our analysis is based on regression analysis, i.e., estimation of the trend as well as application of the $\mathrm{ARCH}$ approach. For estimation purposes, more observations with bigger time span are always better than the fewer observations. Therefore, we divide data into decades and each decade has at least one recession and that implies that each decade contains business cycle properties, e.g., peak and trough. 


\section{Econometrics Set-up}

\section{Unit Root Testing: Introduction}

Dickey and Fuller $(1979,1981)$ introduced the idea of a unit root and proposed a standard unit root testing procedure which is known as ADF (Augmented Dickey-Fuller) test of unit root. But unit root testing became popular in economics, especially among macro-economists, after the publication of the seminal paper by Nelson and Plosser (1982). Nelson and Plosser employed unit root methodology on 14 U.S. macroeconomic time series and they could reject the null hypothesis of a unit root for only one time series, which was the unemployment rate. In addition, Nelson and Plosser concluded that many macroeconomic series are non-stationary. That implies many macroeconomic series exhibit trending behavior or a non-stationary mean-put simply, not mean-reverting. Therefore, unit root tests can be used to characterize a time series. There are many other unit root tests, other than $\mathrm{ADF}$ test, available in the literature. For instance; Phillips-Perron (1988) (PP), and Kwiatkowski-Phillips-Schmidt-Shin (1992) (KPSS) tests of unit root (also known as traditional unit root tests); tests introduced by Elliot-Rothenberg-Stock (1996) (ERS) and Ng-Perron (2001) (also known as efficient unit root tests). We employ all these tests on the U.S. profit growth rate series and test whether the profits series is mean reverting. (Note 7)

\section{Unit root Tests and Structural Breaks}

Perron (1989) challenged Nelson-Plosser (1982) conclusion that most macroeconomic time series contain a unit root. Perron argued that in the presence of a structural break, the standard ADF tests are biased towards the non-rejection of the null hypothesis. He concluded that most macroeconomic time series are not characterized by a unit root but rather that persistence arises only from large and infrequent shocks. In addition, Perron (1989) used the Nelson-Plosser (1982) data set and incorporated an exogenous structural break for the 1929 crash. He reversed the Nelson-Plosser (1982) conclusions for 10 of the 13 macroeconomic time series. However, Perron's assumption of 'known break date' (also known as exogenous break) was criticized, most notably by Christiano (1992) as "data mining". Christiano argued that the data based procedures are typically used to determine the most likely location of the break and this approach invalidates the distribution theory underlying conventional testing. Since then, there are two major views about the break date, which are (a) known or exogenous break date and (b) unknown or endogenous break date. Perron (1989) proposed an exogenous (known) structural break unit root test. Several other studies have developed using different methodologies for endogenously determining the break date, including Banerjee et at. (1992), Zivot and Andrews(1992), Perron and Vogelsand (1992), Perron (1997), Lumsdaine and Papell(1997) and many others.(Note 8) The commonly used unit root test of endogenous break date is introduced by Zivot-Andrews (1992).

The above mentioned tests assumed that there is a break-point and determined the break date either exogenously or endogenously. But the important question is; if there is no break point and we enter a break point into the regression then what happened to the unit root tests results? Nunes et al. (1997) and Bai (1998) provided the answer to the question and the answer is "spurious break". More explicitly, when the disturbances of a regression model follow an $I(1)$ process, order of integration one, there is a tendency to estimate a break point in the middle of the sample, even though a break point does not actually exist. Therefore, unit root tests are not reliable in these cases; (1) when a break point exists and did not include in the test regression, (2) if a break point does not exist and did include in the test regression, and (3) the use of incorrect break date in the test regression. The good thing of the Perron (1989) type's tests is that they are invariant to the break parameters and thus their performance does not depend on the magnitude of the break.

Recently, Kim-Perron (2009) proposed a unit root test with structural break that address these issues and provide a more efficient testing procedure. For instance, Perron (1989) test allow for a break under the null and alternative hypotheses but assume exogenous break and, on the other hand, Zivot-Andrews (1992) test assume endogenous break but did not allow break under the null hypothesis. In addition, both tests did not talk about the "spurious break". Kim-Perron (2009) unit root test allows a break at unknown time under both the null and alternative hypotheses. The test also tackles the issue of "spurious break" and proposed a pre-test for a break that is valid whether the noise component is integrated or stationary (Kim-Perron, 2009).

We discuss unit root test with structural break briefly (for more detail see Kim-Perron 2009; and Silvia-Iqbal; 2009). Perron (1989) introduced the first standard unit root tests with structural break and all others tests are extension or modification of the Perron's test and thereby we start with the Perron test. Perron suggested three models. The models take into account the existence of three kinds of structural breaks: a 'crash' model (Model A), which allows for a break in the level (or intercept) of the series; a 'changing growth' model (Model B), which permits for a break in the slope (or rate of growth); and lastly one that includes both effects to occur simultaneously (Model C), i.e. one time change in both the level and the slope of the series. 
Model (A) $\quad \Delta y_{t}=\gamma+\gamma_{1} D U_{t}+d(D T B)_{t}+\alpha y_{t-1}+\beta t i m e+\sum_{j=1}^{p} \phi_{j} \Delta y_{t-j}+\varepsilon_{t}$

Model (B) $\quad \Delta y_{t}=\gamma+\gamma_{1} D T_{t}^{*}+\alpha y_{t-1}+\beta t i m e+\sum_{j=1}^{p} \phi_{j} \Delta y_{t-j}+\varepsilon_{t}$

Model (C) $\Delta y_{t}=\gamma+\gamma_{1} D U_{t}+d(D T B)_{t}+\gamma_{2} D T_{t}+\alpha y_{t-1}+\beta t i m e+\sum_{j=1}^{p} \phi_{j} \Delta y_{t-j}+\varepsilon_{t}$

Where $y_{\mathrm{t}}$ is dependent variable and profit growth in our case. Time is a time variable or time dummy. The intercept dummy $D U_{t}$ represents a change in the level;

$$
D U_{t}=\left\{\begin{array}{llc}
1 & \text { if } & t>T B \\
0 & & \text { otherwise }
\end{array}\right.
$$

The slope dummy $D T_{t}$ (also $D T_{t}^{*}$ ) represents a change in the slope of the trend function;

$$
D^{*} T_{t}=\left\{\begin{array}{llc}
t & \text { if } & t>T B \\
0 & \text { otherwise }
\end{array}\right.
$$

The crash dummy model;

$$
D T B=\left\{\begin{array}{lll}
1 & \text { if } & t=T B+1 \\
0 & & \text { otherwise }
\end{array}\right.
$$

TB is the break date. It is worth mentioning that each of the three models has a unit root with a break under the null hypothesis, as the dummy variables are incorporated in the regression under the null. The alternative hypothesis is a broken trend stationary process.

The endogenous structural break test of Zivot and Andrews (1992) is a sequential test which utilizes the full sample and uses a different dummy variable for each possible break date. The selection criterion for the break date is based on the t-statistic from an ADF test and a minimum (i.e. most negative) value of t-statistic will be the indication of the break date. Zivot-Andrews test evaluates the joint null hypothesis of a unit root with no break in the series. As a consequence, accepting the null hypothesis in the context of Zivot-Andrews test does not imply unit root but rather unit root without a break. The critical values for Zivot-Andrews tests are derived under the assumption of no structural breaks under the null hypothesis.

Kim and Perron (2009) test allows break under both the null and alternative hypotheses and, when a break is present, the limit distribution of the test is the same as in the case of a known break date, thereby allowing increased power while maintaining the correct size. If there is no break in the trend then we can apply the standard ADF or any other unit root test with no break dummies. Hence, we need a pre-test to assess whether a break is present or not. Kim and Perron (2009) proposed the procedure (Note 9) that has the correct size and powerful whether the noise is stationary or integrated. The testing procedure is based on a quasi-GLS approach using an autoregression of order one for the noise component, which a truncation to 1 when $\alpha$ is in some neighborhood of 1 , and a bias correct. For a given break date, one constructs the F-test for the null hypothesis of no structural change in the deterministic components. Kim and Perron (2009) labeled the test as Exp- $\mathrm{W}_{\mathrm{FS}}$. The test has the same asymptotic size whether the noise is stationary or integrated (see Kim-Perron; 2009 for more detail).

We apply Perron (1989), Zivot-Andrews (1992) and Kim-Perron (2009) tests on the profit growth series and test whether the profits series is mean-reverting as well as subject to a structural change.

\section{Results (Note 10)}

In this paper we first divide the U.S. profit growth series into decades to test if all data share the same statistical moments - mean, standard deviation and stability ratio - and whether there is any change in the characteristic of the trend in profit growth over time. There are two major types of trend-linear and nonlinear. A linear trend explains a constant growth rate and a nonlinear trend is associated with a variable growth rate (see Diebold, 2007 for more detail).

\section{Simple Statistics: the Mean, Standard deviation, Stability ratio and the Trend}

We broke up the profits data since 1970 into decades which roughly approximates four distinct periods of economic performance and political policy orientations. We estimate a mean, standard deviation and stability ratio for each decade. The stability ratio, standard deviation as percent of mean, represents the volatility of the profits series in each decade where the higher value of the stability ratio is an indication of higher volatility. One vital benefit of the 
stability ratio is that it identifies the magnitude of the volatility of profit growth by decade. Without a stability ratio, it is hard to specify profit volatility by decades for researchers. For instance, if we set the standard deviation as the volatility criterion, then the 1970s has highest standard deviation and 1990s has smallest. If we stick with this criterion, then the 1970s is most volatile and 1990s is least. But the problem with this criterion is that the 1970s also has the highest mean and 1990s has the smallest mean. Therefore, standard deviation alone is not the best measure of volatility especially when we compare different decades. Indeed, we need to consider both mean and standard deviation to determine stability in profit growth by decades. The stability ratio includes both mean and standard deviation and gives us information about which decade has a higher standard deviation relative to the mean for profit growth. Based on the stability ratio we conclude that 1980s is most volatile and 1990s is most stable decade for profit growth.

For the 1970s period, profit growth contains a trend, in that, the coefficients of the time variable (time dummy) are statistically significant and that the trend is nonlinear and perhaps more like an inverted U-shaped. The standard deviation $(14.67 \%)$ is higher than the mean $(9.83 \%)$ and the stability ratio is 149 (standard deviation is 149 percent of the mean). Unfortunately, as we continue testing over subsequent decades we find that the results of the 1970s are not repeated during the $1980 \mathrm{~s}$ - a decade of apparent prosperity and stock market gains relative to the 1970s. During the $1980 \mathrm{~s}$, the standard deviation (14.02\%) of profit growth appears very large relative to its average values (7.57\%). In addition, the stability ratio (185.2) is higher than during 1970s, in fact, the highest in the entire sample. During the 1990s, the standard deviation and the mean follow the decreasing pattern of the previous two decades. But the reduction in the standard deviation is much higher than the drop in the mean. Therefore, the stability ratio (108.58) is much smaller, in fact smallest in the entire period. The 1980s and 1990s have a nonlinear, inverted U-shaped trend. For the most recent (2000-08) period, the profit growth shows an uptick in both the mean and the standard deviation and follow an inverted U-shaped trend.

Our efforts suggest that since 1970 the mean and standard deviation of profit growth had actually been decreasing up until 1990s. When we evaluate the entire period as a whole, 1970-2008, we find that the trend coefficient is statistically insignificant. In addition, a higher standard deviation $(12.43 \%)$ than the mean $(8.19 \%)$ is evidence of high volatility in the profits series. Indeed, the growth of profits is very volatile over time as pictured by Figure 1. Public policy decisions (taxes and expenditures) as well as exogenous factors (oil price spikes) may account for the difference in volatility of corporate profits between decades.

\section{Unit Root Tests without Structural Break}

Table 2 shows results based on unit root tests (Note 11) and these tests do not consider a structural break in the test regression as well as in the null and the alternative hypotheses. We start with the ADF test's results. First case, we consider within the ADF test the zero-mean case (no intercept and trend in the test regression). Ng and Perron (2001) suggested that the Modified Akaike Information Criterion (MAIC) is a better choice for the lag order selection thereby we select lag length based on MAIC. (Note 12) We reject the null hypothesis that the profit series has a unit root (not mean-reversion) in favor of the alternative hypothesis that the profit series is stationary (mean-reversion). In second case, we incorporated a constant (also known as drift parameter) in the test regression but results did not show any change and the profit series is still mean-reverting (stationary). The third case which includes a constant and a linear trend in the test regression and the result is as rejection of the null hypothesis of a unit root. Therefore, based on the ADF test results, the profit growth series is mean reverting.

The next unit root test we applied on the profit growth series is the PP test. The PP test has the null hypothesis of a unit root and the alternative is stationary (mean-reversion). We ran three different regression equations which are (i) equation with no intercept and trend, (ii) regression equation with constant and (iii) test equation with a constant and a linear trend. The results based on the PP test indicate strong evidence of mean-reversion. In other words, in all three cases we reject the null hypothesis of a unit root and conclude that the profits series is mean-reverting. We also applied the KPSS test on the profit growth series. The null hypothesis of the KPSS test is that the underline series is stationary (in our case, the profit series is stationary) and the alternative hypothesis is non-stationary. The KPSS test only considers two cases which are (a) test regression with a constant and (b) regression equation with a constant and a linear trend. We failed to reject the Ho: the profits series is stationary in both cases thereby the KPSS test results indicate that the U.S. profit growth series is mean-reverting.

Interesting, all three unit root tests have the same conclusion, that is, the level of the profit growth series is mean-reverting. However, the ADF, PP and KPSS tests have some limitations and may lead to a misleading conclusion. (Note 13) Therefore, we employ efficient and more reliable unit root tests which are ERS (DF-GLS and Point-optimal tests) and Ng-Perron tests. The results based on ERS and Ng-Perron tests are also available in Table 2. The DF-GLS test has the null hypothesis of a unit root and the alternative is stationary. We failed to reject the null hypothesis of a unit root in both cases; (i) a constant in the test regression and (ii) a constant and a linear trend in the regression. Therefore, the DF-GLS test results contradict the ADF, PP and KPSS tests' results. Moreover, the 
DF-GLS test indicates that the level of the profit growth series is not mean-reverting. However, the first difference of the profit growth series is stationary. (Note 14)

The next unit root test we applied on the profit series is the ERS Point-optimal unit root test which has the null hypothesis of a unit root and the alternative hypothesis is stationary (mean-reversion). When we include a constant in the test regression then we reject the null hypothesis that the profit series has a unit root at $10 \%$ level of significance. That implies the profit growth series is mean reverting. However, when we include a constant and a linear trend in the test regression then the result rejects mean-reversion assumption, the level of the profit series has a unit root. But the first difference of the profit growth series is stationary. Although the ERS point-optimal unit root test has a confusing conclusion, if we set the level of significance as $5 \%$ then we fail to reject the null hypothesis of a unit root. Now we proceed to the more efficient test of unit root and that is Ng-Perron tests. The results based on the Ng-Perron tests indicate that the profit growth series contains a unit root. In other words, the profits series is not mean reverting.

In sum, based on the unit root tests without structural break, we conclude that the level of the U.S. profit growth rates is not mean-reverting. Although, the ADF, PP, and the KPSS tests' results are in favor of the mean-reversion, these tests have lower power than the ERS and Ng-Perron tests. Therefore, we give more importance to those results which are based on the ERS and Ng-Perron tests. (Note 15)

\section{Unit Root Tests with Structural Break}

In this section of the study we discuss the results based on the unit root tests which incorporate a structural break. We utilized the Perron (1989) test and consider 1973:Q4 as a break date. (Note 16) We failed to reject the null hypothesis of a unit root with a structural break. That implies, the profits series is not only mean diverting but also has a structural break and the break date is 1973:Q4. The next test we applied on the profit growth series is the Zivot-Andrews test. We test different options for a break date. For instance, 1973:Q4-1975:Q1 (time duration of the 1973-75 recession), 1981:Q3-1982:Q4 (time duration of the 1981-82 recession) and 1987:Q3 (for 1987 stock market crash). We try one by one each quarter of the above mentioned time period. We end up 1975:Q1 as a break date and this is based on the Zivot-Andrews sequential test. The null hypothesis of the Zivot-Andrews test is a unit root with no structural break. The results based on the Zivot-Andrews test fail to reject the null hypothesis and conclude that the profit growth series is mean diverting. The Zivot-Andrews test's results are not in favor of a structural break but the Perron test supports the idea of a structural break in the profit growth series. The Zivot-Andrews test does not assume a structural break under the null and the alternative hypotheses but the Perron test allows for a break under the null and alternative hypotheses. Nunes et al. (1997) suggested that there may be some size distortion for Zivot-Andrews test.

The first step of the Kim-Perron procedure is a pre-test for the break date. We apply the EXP- $\mathrm{W}_{\mathrm{FS}}$ test and found that profit growth series has a structural break and that is 1973:Q4. Next step would be to follow the Kim-Perron unit root test and determine whether profit growth contains a unit root. Based on the Kim-Perron test results, we fail to reject the null hypothesis that profit growth contains a unit root as well as subject to a structural break for all three models. The Kim-Perron unit root test is the most efficient test and thereby, based on the Kim-Peron test, we conclude that profit growth series contains a unit root and subject to a structural break in our sample period.

\section{ARCH Results (Note 17)}

We have found that the level of the profit growth series is non-stationary, mean-diverting, that implies that the mean and/or variance of the profits series are not constant over time and may be time dependent. But it is still important to analyze the behavior of the profits series' variance and test whether the variance is volatile over time; it is also known as the ARCH effect. The ARCH effect has very serious consequences for modeling and forecasting. For instance, in the presence of the ARCH effect OLS standard errors can be misleading, with a spurious regression possibility (see Hamilton; 2008 for more detail). Another issue would be that the forecast band could be narrower than the actual. We divided the sample period into decades and applied an ARCH Approach on each decade's data as well as the complete sample that is 1970:Q1-2008:Q4. We found an ARCH effect for each decade as well as for the complete sample period. (Note 18) The implication of the ARCH effects is that the profit growth series has a volatility cluster - some periods are more volatile than others. In other words, the variance of the profit growth series is not constant over time and may have episodes of high variance for some periods. That also implies, the forecast band, upper and lower band of the forecast, will not be constant and may be smaller for some time period than others, and vice versa.

If we sum-up our empirical analysis, then the level of the profit growth rates is mean diverting and subject to a structural break. The ARCH effect tells us the profit growth series has a volatility cluster- some periods are more volatile than others. 


\section{The Theoretical and Practical Implication of the Results}

Theoretically, our finding of mean-diversion is consistent with the Schumpeter's view, that is, deviation from equilibrium may leads to a new equilibrium. Put simply, due to several factors: introduction of new goods, new method of production, introduction of a new market, new source of input supply, and carrying out of the new organization of any industry; profits may not return to their normal level, long-run trend growth. Moreover, these factors may change the long-run path of the profits, a structural change in the trend growth. Our finding of the $\mathrm{ARCH}$ effect is supporting the idea that profits may deviate from their long-run trend growth. In addition, this deviation is not constant over time, that is, deviation from normal profits in some periods is more than other periods.

In real world, there are many examples which support the Schumpeterian view and justify the mean-diversion of the profits. For example, in case of introduction of new goods: personal computers by Microsoft and copy machine by Xerox, etc. Due to trade liberalization many new markets open to firms and concept of multi-national firms emerge. In addition to the factors introduced by Schumpeter (1934, chapter 2) there are some exogenous shocks which could alter the long-run trend growth of profits. For instance, due to 1973 oil price shock, some people believe it is the end of the cheap energy era, input prices rose sharply and production technologies were rendered obsolete, as a result the profits' long-run growth path shift to another level— we called it a structural change. Therefore, our finding of a structural change in the profits is consistent with this view.

Summing-up, our empirical findings are consistent with the Schumpeter's view, mean-diversion with a possibility of deviation from long-run trend growth. In addition to the factors introduced by Schumpeter there may be some exogenous shocks which could alter the long-run growth path of the profits.

\section{Conclusion}

Corporate profits provide the return to capital that sustains the incentive to invest for U.S. corporations and investors. The search for profits by entrepreneurs and corporate leaders is one of the key incentives to technology development, efficient organization and development of physical and human capital. This paper seeks to characterize the behavior of profits over the economic cycle. We raise three fundamental questions, which are; first, does the profit growth over time exhibit a mean-reverting behavior? That is, does the growth in profits exhibit a tendency to return to some average value? Second, how volatile are profits and does this volatility obscure the message of profit growth? Finally, do profit growth rates vary between decades/ sub-samples?

Our efforts suggest that since 1970 the mean and standard deviation of profit growth had actually been decreasing up until 1990s. For the most recent (2000-08) periods, the profit growth shows an uptick in both the mean and the standard deviation. When we evaluate the entire period as a whole, 1970-2008, we find that the trend coefficient is statistically insignificant. In addition, the higher standard deviation $(12.43 \%)$ than the mean $(8.19 \%)$ is evidence of high volatility in the profits series.

Our empirical findings are consistent with the Schumpeter's view, mean-diversion with a possibility of deviation from trend growth. In addition to the factors introduced by the Schumpeter there may be some exogenous shocks which could alter the long-run growth path of the profits.

If we sum-up our empirical analysis then the level of the profit growth rates is mean-diverting and subject to a structural break. Therefore, the level of the profits series is not appropriate for the modeling and forecasting purpose because of a unit root problem. Second, due to the presence of a structural break in the profits series it would be better to employ only those techniques which are assuming a structural break in the data e.g., cointegration tests with a structural break. Third, in the presence of the ARCH effect, OLS standard errors can be misleading, with a spurious regression possibility in which a true null hypothesis is asymptotically rejected with probability one. Fourth, the ARCH effect and unit root problem have serious consequences for forecasting and the forecast band could be narrower than the actual. Finally, due to the unit root, a structural break and the ARCH effect, more care is required for modeling and forecasting the profits series.

\section{References}

Bai, J.(1998). A Note on Spurious Break. Econometric Theory, vol. 14(05), 663-669.

Banerjee, A., Lumsdaine, R. \& Stock, J.H. (1992). Recursive and sequential tests of unit-root and the trend break hypotheses: theory and international evidence. Journal of Business Economics and Statistics, 10, pp271-287.

Christiano, L.J. (1992). Searching for a break in GNP. Journal of Business Economics and Statistics, 10, pp237-250. Clemente, J., Montanes, A., \& Reyes, M. (1998). Testing for a unit root in variables with a double change in the mean. Economics Letters, 59(2), pages 175-182.

Dickey, D.A. \& Fuller, W.A. (1979). Distribution of the estimators for autoregressive time series with a unit root. Journal of the American Statistical Association, 74, 427-431. 
Dickey, D.A. \& Fuller, W.A. (1981). Likelihood Ratio Statistics for Autoregressive Time Series with a Unit Root. Econometrica, 49, 1057-1072.

Diebold, F. X. (2007). Elements of Forecasting. $4^{\text {th }}$ ed., Thomson South-Western.

Elliott, G., Rothenberg, T. \& Stock, J. (1996). Efficient Tests for an Autoregressive Unit Root. Econometrica 64, $813-836$.

Giovannoni, O \& Parguez, A. (2005). What Drives Profits? An Inquiry into the Profit Paradox. The 2005 Eastern Economic Association conference, March 4-6, NY, USA. Available at: http://aix1.uottawa.ca/ robinson/english/workshop_paper/2005/Parguez_Giovannoni.pdf

Hamilton J. D. (2008). Macroeconomics and ARCH, Forthcoming in Festschrift in Honor of Robert F. Engle. Available at http://dss.ucsd.edu/ jhamilto/JHamilton_Engle.pdf

Kwiatkowski, D., Phillips, P., Schmidt, P. \& Shin, Y. (1992). Testing the null hypothesis of stationarity against the alternative of a unit root: How sure are we that economic time series have a unit root? Journal of Econometrics 54(1-3):159-178.

Kim, D. \& Perron, P. (2009). Unit root tests allowing for a break in the trend function at an unknown time under both the null and alternative hypotheses.Journal of Econometrics, 148, pp1-13.

Lipczinsky, J. \& Wilson, J. (2001). Industrial Organization: An Analysis of Competitive Markets. Prentice Hall, UK. Lumsdaine, R.L. \& Papell, D.H. (1997). Multiple trend breaks and the unit root hypothesis. Review of Economics and Statistics, 79, 212-218.

Mueller, D. C. (1977). The Persistence of Profits above the Norm, Economica, vol. 44, No. 176,

Mueller, D. C. (1990). The Dynamics of Company Profits: an International Comparison, Cambridge University Press.

Nelson, C. R. \& Plosser, C. I. (1982). Trends and random walks in macroeconomics time series: some evidence and implications. Journal of Monetary Economics, 10, 139-162.

Ng, S. \& Perron, P. (2001). Lag length selection and the construction of unit root tests with good size and power. Econometrica, 69, 1519-1554.

Nunes, L., Kuan, C. \& Newbold, P(1997).Spurious break. Econometric Theory, 11 736-49.

Papell, D. H. \& Prodan, R. (2006). Restricted Structural Change and the Unit Root Hypothesis. Working paper, University of Houston; available at http://www.uh.edu/ dpapell/pp2.pdf

Perron, P. (1989). The great crash, the oil price shock and the unit root hypothesis. Econometrica, 57, 1361-1401.

Perron, P. (1997). Further evidence on breaking trend functions in macroeconomic variables. Journal of Econometrics, 80, 355-385.

Perron, P \& Vogelsang, T. (1992). Testing for unit root in a time series with a changing mean: correction and extension. Journal of Business and Economic Statistics, 10, 467-470.

Perron, P \& Yabu, T. (2009). Testing for shifts in the trend with an integrated or stationary noise component. Journal of Business and Economic Statistics.

Phillips, P. \& Perron, P. (1988). Testing for a unit root in time series. Biometrika, 75, pp1361-1401.

Schumpeter, J. A.(1934). The Theory of Economic Development, Cambridge, MA: Harvard University Press; first published in German, pp.1911.

Schumpeter, J. A. (1950). Capitalism, Socialism and Democracy, New York: Harper and Row.

Silvia, J. and Iqbal, A. (2009). Mean Diversion: When Getting Back to the Old Economy Isn't Possible: Southern Economic Association, 79 $9^{\text {th }}$ Annual Meetings, November 2009, TX, USA. Available at http://www.ccsenet.org/journal/index.php/ijef/article/view/8207

Uctum, M. (1995). The Evolution and Determinants of Corporate Profits: An International Comparison. Federal Reserve of New York, Research Paper No. 9502. available at http://www.newyorkfed.org/research/staff_reports/research_papers/9502.pdf.

Zivot, E. \& Andrews, D. (1992). Further evidence on the great crash, the oil price shock and the unit root hypothesis. Journal of Business and Economic Statistics, 10, 251-270.

\section{Notes}

Note 1. We plotted original series in figure 1.

Note 2. See section Econometric Set-up for more detail. 
Note 3. Frank H. Knight, Risk, Uncertainty, and Profit, 1921, Houghton Mifflin Co., Chapter 2.

Note 4. Robert M. Solow, "A Contribution to the Theory of Economic Growth," Quarterly Journal of Economics (February 1956): 65-94.

Note 5. Internally, we do examine subcomponents but for this paper we study the aggregate series. One major issue with the subcomponents of the profits is that the data is not available for a longer time period. For instance, subcomponents such as corporate profit: financial sector and for non-financial sector only go back to 2001:Q1. Therefore, we are concentrating on aggregated profits data series.

Note 6. We are using quarterly profit growth series, year-over-year percent change. The full name of the series is (nominal) Corporate Profit with Inventory Adjusted and Capital Consumption Adjustment, billions of U.S. dollar, seasonally adjusted at annual rate, NIPA, Table 1.7.5, Bureau of Economic Analysis (BEA). We will use corporate profits, profit growth and profits interchangeably.

Note 7. Here we are not explaining these tests in detail because of space limit. See Silvia and Iqbal (2009) for more detail.

Note 8 . It is worth mentioning that many researchers are considering multiple structural breaks. The argument for incorporating more than one break is that only considering one break is insufficient and leads to a loss of information when actually more than one break exits. Lumsdaine and Papell (1997), Clemente et al. (1998), and Papell and Prodan (2006) considered multiple breaks. But we are not using multiple breaks test in this study because our analysis starts, sample start date, from 1970 and it is relatively a short history. Therefore, we only employ single break tests, both exogenous and endogenous breaks test.

Note 9. It is worthwhile to mention that this procedure originally introduced by Perron and Yabu (2009).

Note 10. See Table 1 for summary of the results.

Note 11. Best of our knowledge, we are the first who apply a comprehensive unit root methodology on the U.S. profit growth series.

Note 12. See Ng and Perron (2001) for more detail.

Note 13. See Silvia and Iqbal (2009) for more detail.

Note 14 . We are only reporting the results for the level of the profit growth series because we are interested in the mean reverting properties of the profit growth series. However, we also estimate the results for the first difference. All results and data are available upon request from authors.

Note 15. Although, ERS point-optimal test is rejecting Ho: the profits series has a unit root, at $10 \%$ level of significance but the standard level of significance is $5 \%$ and at 5\% ERS failed to reject the null hypothesis of a unit root.

Note 16. We are considering 1973:Q4 as break date because this date is the beginning of the 1973-75 recession. This recession is famous for the initial Post World-War-II oil shock and, due to the oil shock, energy input prices rose sharply, production technologies were rendered obsolete and hence the profit growth rates become volatile.

Note 17. The results are reported in Table 1.

Note 18. It is worth mentioning that we used the level and 1st difference of the profit growth series and found $\mathrm{ARCH}$ effect in both cases.

Acknowledgement: Initial draft of this paper was presented at the $68^{\text {th }}$ International Atlantic Economic Conference, October 2009, Boston, MA, USA. We are grateful to the audience of the conference for their useful comments. The views expressed in this study are those of the authors. Neither Wells Fargo Corporation nor its subsidiaries is responsible for the contents of this article. 
Table 1.

\begin{tabular}{|l|l|l|l|l|l|l|}
\hline \multicolumn{3}{|c|}{ The U.S. Corporate Profits, Year-over-Year Percent Change } \\
\hline Period & Mean & S.D* & Stability Ratio** & Trend & ARCH/GARCH & Comments \\
\hline $1970-79$ & 9.83 & 14.67 & 149.24 & $\begin{array}{l}\text { Nonlinear: } \\
\text { Inverted } \\
\text { U-shaped }\end{array}$ & ARCH effect & Highest mean and S.D. \\
\hline $1980-89$ & 7.57 & 14.02 & 185.2 & $\begin{array}{l}\text { Nonlinear: } \\
\text { Inverted } \\
\text { U-shaped }\end{array}$ & ARCH effect & $\begin{array}{l}\text { S.D is higher than mean. Highest stability ratio, } \\
\text { most volatile decade. }\end{array}$ \\
\hline $1990-1999$ & 7.46 & 8.1 & 108.58 & $\begin{array}{l}\text { Nonlinear: } \\
\text { Inverted } \\
\text { U-shaped }\end{array}$ & ARCH effect & $\begin{array}{l}\text { A very different structure than previous two } \\
\text { decade, much lower S.D which is a sign of } \\
\text { stability as compare to last two decades. Smallest } \\
\text { stability ratio. }\end{array}$ \\
\hline $1970-2008$ & 8.19 & 12.43 & 151.77 & $\begin{array}{l}\text { Nonlinear: } \\
\text { Inverted } \\
\text { U-shaped }\end{array}$ & ARCH effect & $\begin{array}{l}\text { S.D is higher than mean, a sign of high volatility. } \\
\text { Higher stability ratio, more volatile decade. }\end{array}$ \\
\hline
\end{tabular}

* S.D $=$ Standard Deviation

** Stability Ratio $=($ S.D/Mean $) \times 100$

Table 2. Unit Root Tests; Without Structural Break

\begin{tabular}{|lccc|}
\hline Test Name & Constant & Test Option & Constant \& Trend \\
ADF & No & No & No \\
PP & No & No & No \\
KPSS & No & No & N/A \\
DF-GLS & Yes & Yes & N/A \\
ERS & No & Yes & N/A \\
Ng-Perron & Yes & Yes & N/A \\
\hline
\end{tabular}

No $=$ No unit root --- Mean-reversion

Yes $=$ unit root ---- not Mean-reversion

$\mathrm{NA}=$ Option not available in the test regression

Table 3. Unit Root Tests; With Structural Break

\begin{tabular}{|lccc|}
\hline \multicolumn{1}{r}{ Test Name } & Model A & Test Option & \\
Perron* & Yes & Model B & Model C \\
Zivot-Andrews** & Yes & Yes & Yes \\
Kim-Perron*** & Yes & Yes & Yes \\
\hline
\end{tabular}

No $=$ No unit root --- Mean-reversion

Yes $=$ Unit root ---- Not Mean-reversion

* Break Date $=1973: 4 Q$

** Break Date $=1975:$ Q1

*** Break Date= 1973:Q4 


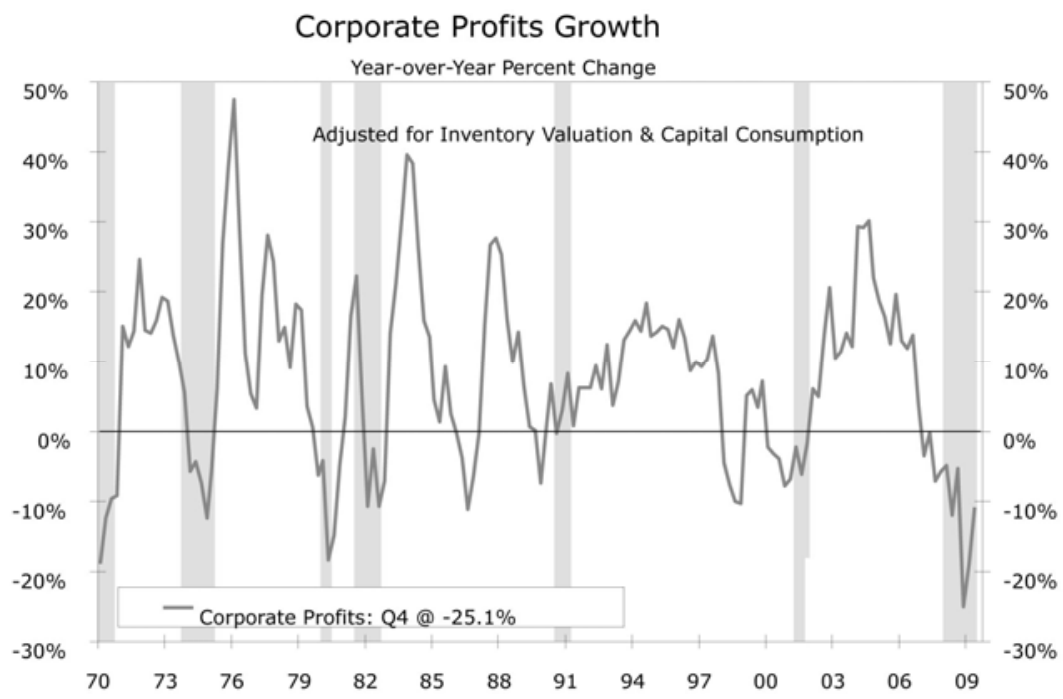

Source: U.S. Department of Commerce and Wells Fargo Securities, LLC

Figure 1. 